\title{
Pharmacologic and Non-Pharmacologic Treatment of Chronic Atrial Fibrillation - With Special Reference to Valvular Atrial Fibrillation in Rheumatic Heart Disease
}

\author{
Mohan Nair, Sanjeeb Patra and Vanita Arora \\ Max healthcare Superspeciality Hospital, New Delhi \\ India
}

\section{Introduction}

Atrial fibrillation (AF), the most commonly encountered arrhythmia in clinical practice, is associated with significant morbidity and mortality. Of great significance are heart failure and stroke. ${ }^{1}$ With increased incidence and prevalence of AF, it represents a growing clinical and economic burden. AF is also a progressive disease secondary to continuous structural remodeling of the atria because of $\mathrm{AF}$ itself, to changes associated with ageing and to deterioration of underlying heart disease. Current management aims at preventing the recurrence of $\mathrm{AF}$ and its consequences and includes risk assessment and prevention of stroke, control of ventricular rate and rhythm control therapies including antiarrhythmic drugs and catheter or surgical ablation.

\section{Classification}

The nomenclature used to classify AF has been diverse. AF can be acute (first detectable episode whether symptomatic or not) or chronic (paroxysmal, persistent, and long-standing persistent), or finally permanent. According to a consensus document ${ }^{2}$, paroxysmal AF is defined as at least two episodes that terminate spontaneously within 7 days. Persistent AF is defined as lasting more than 7 days, or lasting less than 7 days but necessitating pharmacologic or electrical cardio version. Permanent AF is defined as lasting more than 1 year.

These definitions apply only to episodes that last at least 30 seconds and have no identifiable reversible cause, such as acute pulmonary disease or hyperthyroidism. Both paroxysmal and persistent atrial fibrillations are potentially recurrent arrhythmias. Paroxysmal atrial fibrillation may become persistent with time; and both paroxysmal and persistent AF may become permanent.

The term "lone atrial fibrillation" refers to AF in young people (aged under 60) in whom no apparent cause can be identified.

\section{Pathophysiology}

The exact mechanisms by which cardiovascular risk factors predispose to AF are not understood fully but are under intense investigation. Catecholamine excess, hemodynamic 
stress, atrial ischemia, atrial inflammation, metabolic stress, and neurohumoral cascade activation are all purported to promote AF. Although the precise mechanisms that cause AF are incompletely understood, AF appears to require both an initiating event and a permissive atrial substrate. AF results from multiple re-entrant electrical wavelets that move randomly around the atria. These wavelets are initiated by electrical triggers, commonly located in the myocardial sleeves extending from the left atrium to the proximal $5-6 \mathrm{~cm}$ portions of the pulmonary veins ${ }^{3}$. Other sites in the left and right atria and in the proximal superior vena cava may less frequently trigger atrial fibrillation ${ }^{4,5}$. Once triggered, the atrial tissue harbors these wavelets and promotes re-entry, thus facilitating persistence of the arrhythmia. A period of AF initially induces electrophysiological changes ("electrical remodeling") followed by structural changes ("structural remodeling"), which facilitate its persistence- hence the phrase "atrial fibrillation begets atrial fibrillation"6,7.

\begin{tabular}{|c|c|}
\hline \multicolumn{2}{|c|}{ Common causes of Atrial Fibrillation } \\
\hline $\begin{array}{l}\text { Cardiovascular } \\
\text { - } \quad \text { Rheumatic heart disease } \\
\text { - } \quad \text { Hypertension } \\
\text { - Coronary artery disease } \\
\text { - } \quad \text { Nongestive heart failure } \\
\text { - } \quad \text { Sick sinus syndrome } \\
\text { - } \quad \text { Nolf-Parkinson-white syndrome } \\
\text { - } \quad \text { Endocarditis } \\
\text { - Cardiomyopathy } \\
\text { - Congenital heart disease }\end{array}$ & $\begin{array}{l}\text { Non-cardiovasular } \\
\text { - } \quad \text { Endocrine } \\
\text { (e.g.,Hyperthyroidism) } \\
\text { - Respiratory causes (e.g., pneumonia, } \\
\text { pulmonary thromboembolism) } \\
\text { - Alcohol and drug use }\end{array}$ \\
\hline
\end{tabular}

Atrial fibrillation with poor ventricular rate control can cause electrical and structural remodeling of the ventricle, leading to ventricular dilatation and impairment of systolic function, known as "tachycardia induced cardiomyopathy".

Stroke and thromboembolism are a major cause of mortality and morbidity associated with $\mathrm{AF}$, and the underlying pathophysiological basis of this is a prothrombotic or hypercoagulable state, in association with abnormalities of blood flow (atrial stasis, for example) and endothelial or endocardial damage.

The concept of primary prevention of AF with interventions targeting the development of substrate and modifying risk factors for AF has emerged as a result of recent experiments that suggested novel targets for mechanism-based therapies.

Upstream therapy refers to the use of non-antiarrhythmic drugs that modify the atrial substrate- or target-specific mechanisms of AF to prevent the occurrence or recurrence of the arrhythmia. Angiotensin converting enzyme inhibitors (ACEIs) and angiotensin receptor blockers (ARBs) may be effective in AF prevention in patients with hypertension, left ventricular hypertrophy, and congestive heart failure, as well as in post myocardial infarction patients with depressed left ventricular function ${ }^{8}$. Also statins and omega-3 polyunsaturated fatty acids, and possibly corticosteroids. Animal experiments have compellingly demonstrated the protective effect of these agents against electrical and structural atrial remodeling in association with AF. The key targets of upstream therapy are 
structural changes in the atria, such as fibrosis, hypertrophy, inflammation, and oxidative stress, but direct and indirect effects on atrial ion channels, gap junctions, and calcium handling are also applied. Although there have been no formal randomized controlled studies (RCTs) in the primary prevention setting, retrospective analyses and reports from the studies in which AF was a pre-specified secondary endpoint have shown a sustained reduction in new-onset $\mathrm{AF}$ with $\mathrm{ACEIs}$ and $\mathrm{ARBs}$ in patients with significant underlying heart disease (e.g. left ventricular dysfunction and hypertrophy), and in the incidence of AF after cardiac surgery in patients treated with statins.

\section{Management of AF}

AF management creates a high economic burden because of the concomitant presence of heart failure, coronary artery disease, hypertension, and the need for frequent hospitalizations. Expensive antiarrhythmic drugs and interventional procedures are other important factors that raise the costs of AF care.

Four major aspects should be considered in the AF management ${ }^{9}$ :

i. Symptom control by slowing ventricular response during paroxysmal or persistent AF and long-term rate control in permanent $\mathrm{AF}$

ii. Cardioversion to sinus rhythm

iii. Maintenance of sinus rhythm after successful cardioversion

iv. Prevention of complications and thromboembolic events.

Rhythm versus Rate Control

In order to prevent the complications and symptoms of AF two main strategies exist.

1. Rhythm control: converting the patient's rhythm to sinus and maintaining the sinus rhythm.

2. Rate control: slowing the ventricular response rate without insisting on conversion to sinus rhythm.

The initial therapy after onset of AF should always include adequate antithrombotic treatment and control of the ventricular rate. The goal is to control the ventricular rate adequately whenever recurrent AF occurs.

From a theoretical point of view, converting AF into sinus rhythm is the best option. Nonetheless; the most important trials reported in the existing literature thus far have mentioned no significant difference in terms of quality of life and other outcomes between the two strategies. It seems that the side effects of antiarrhythmic agents (pro-arrhythmia) in the long term, poor efficacy of drugs in the maintenance of sinus rhythm, and inappropriate discontinuation of anticoagulants in the patients who still have AF episodes can interfere with good results in the rhythm-control $\mathrm{arm}^{27}$. Therefore, many experts believe that rhythm control with safe antiarrhythmic drugs or catheter ablation will play an important role in the AF management.

The main agents for slowing ventricular response in AF are beta blockers, calcium channel blockers, and digoxin ${ }^{28}$. Beta-blockers and calcium channel blockers are first-line agents for rate control in atrial fibrillation. These drugs can be administered either intravenously or orally. They are effective at rest and with exertion. Caution should be exercised in patients with reactive airway disease who are given beta-blockers. Digoxin is sometimes used in the acute setting but does little to control the ventricular rate in active patients. As such, it is rarely used as mono therapy. The therapeutic window for digoxin as mono therapy for rate control is narrow and would typically yield toxic levels. Thus, there may be circumstances 
that this drug is used as adjunctive therapy to beta-blockers or calcium channel blockers. Caution should be exercised in elderly patients and those with renal failure receiving digoxin. Digoxin is indicated in patients with heart failure and reduced LV function.

Amiodarone has a Class IIa recommendation from the ACC/AHA/ESC for use as a rate controlling agent for patients who are intolerant of or unresponsive to other agents. Caution should be exercised in those not receiving anticoagulation as amiodarone can promote cardioversion.

Criteria for rate control vary with patient age but usually involve achieving ventricular rates between 60 and $80 \mathrm{bpm}$ at rest and between 90 and $115 \mathrm{bpm}$ during moderate exercise.

The potential benefits of strict (resting heart rate $<80 \mathrm{bpm}$, heart rate $<110 \mathrm{bpm}$ during moderate exercise) versus lenient (resting heart rate $110 \mathrm{bpm}$ ) rate control were addressed in the RACE II trial of patients with permanent AF29. The RACE II study shows that lenientrate control $<110 \mathrm{bpm}$ is not inferior to strict-rate control $<80 \mathrm{bpm}$. As lenient-rate control is generally more convenient, requiring fewer outpatient visits and examinations, lenient-rate control may be adopted as a reasonable strategy in patients with permanent $\mathrm{AF}$. In the AFFIRM study, there was no survival difference between rate-control and rhythmcontrol strategies. In addition, the lower risk of adverse drug effects in the rate-control arm conferred some advantages in this arm. A post-hoc analysis of the AFFIRM data proved that there was no significant benefit in the rhythm-control group versus the rate-control group in patients with $\mathrm{AF}$ and left ventricular dysfunction ${ }^{30}$. The RACE study showed that for the prevention of cardiovascular mortality and morbidity in $\mathrm{AF}$, rhythm control was not superior to rate control ${ }^{31}$. In the PIAF trial, clinical outcomes were similar between the rate-control group and the rhythm-control group but exercise tolerance was better in the rhythm-control arm ${ }^{32}$.

However rhythm-control strategy is more popular than the rate-control strategy worldwide. Symptom control and quality of life generally are better when sinus rhythm is restored and maintained. Treatment analysis from the AFFIRM study ${ }^{42}$ showed that the presence of sinus rhythm was associated with a $47 \%$ reduction in mortality and that the use of AAD was associated with a significant increase in mortality of $49 \%$, suggesting a potential benefit of sinus rhythm maintenance in a non-pharmacological manner.

We hope that with the advent of new drugs for both rhythm control and anticoagulation, maintenance of sinus rhythm after cardioversion can be a more realistic goal.

\subsection{Cardioversion to sinus rhythm}

As a result of atrial remodelling, the longer the duration of AF the less successful is the cardioversion. Predictors of recurrence of AF include long standing atrial fibrillation (duration greater than three months), heart failure, structural heart disease, hypertension, increasing age (over 70), and increased left atrial size ${ }^{10}$.

Although left atrial size is related to the duration of AF, a left atrial diameter greater than 6.5 $\mathrm{cm}$ is associated with an increased risk of recurrence ${ }^{11}$.

Cardioversion carries a 5-7\% risk of thromboembolism without anticoagulation and a 1-2\% risk after conventional anticoagulation ${ }^{12}$. Prolonged anticoagulation is not needed when patients present within 48 hours of onset of AF. Such patients may be safely cardioverted irrespective of whether heparin has been administered since presentation. Administration of heparin is recommended to all patients with an acute presentation, however, to allow flexibility in subsequent management of the arrhythmia ${ }^{13}$. 
For stable patients, in whom the onset of AF is uncertain or greater than 48 hours, anticoagulation for a minimum of three weeks before cardioversion is recommended, to allow resolution of potential thrombi. As atrial mechanical activity may not resume concurrently with electrical activity, anticoagulation should be continued for at least four weeks after cardioversion.

An alternative approach is to use transoesophageal echocardiography to exclude atrial thrombi before cardioversion is attempted. The presence of an atrial thrombus necessitates four to six weeks of anticoagulation before cardioversion. Even with this strategy, anticoagulation should be continued for at least four weeks after cardioversion.

\subsection{Pharmacological cardioversion}

Pharmacological cardioversion should be reserved for haemodynamically stable patients with symptoms. In general, class I and class III antiarrhythmic agents are commonly used for pharmacological cardio version and maintenance of sinus rhythm. In AF episodes lasting less than 48 hours cardio version rate for class IC and III drugs is approximately $60-80 \% 14$.

In a randomised trial comparing flecainide, propafenone, and amiodarone for cardioversion of recent onset AF, conversion to sinus rhythm occurred in $90 \%, 72 \%$, and $64 \%$ of patients respectively 15 . Class IC drugs (flecainide and propafenone) should be avoided in patients with underlying ischaemic heart disease or impaired left ventricular function. Amiodarone can be used in such patients, although the time to conversion can range from days to weeks.

Ibutilide is a class III antiarrhythmic agent that can convert AF to sinus rhythm more rapidly than can procainamide or sotalol. It has been shown that ibutilide has no significant advantage compared with amiodarone for the conversion of AF but severe hypotension was not seen with ibutilide 23 . For acute AF, conversion to sinus rhythm with ibutilide is about $59 \%$, but there is $1.7 \%$ risk of polymorphic ventricular tachycardia with this drug. As a result, it is advised to keep the patients receiving ibutilide under monitoring for at least 24 hours after the infusion of this drug 24 .

Dofetilide is another class III antiarrhythmic drug that can be used for maintaining sinus rhythm in congestive heart failure patients with AF. The DIAMOND CHF trial showed that it could reduce hospitalization due to heart failure. Heart failure worsening was reduced by $25 \% .{ }^{25}$ Dofetilide is known to be more effective in patients with persistent AF compared with those with paroxysmal AF, and significant proarrhythmic adverse effects can occur even with close monitoring.

Vernakalant is an atrial-selective drug treatment for atrial fibrillation which affects $\mathrm{Na}+$ and several $\mathrm{K}+$ channels in the heart. Vernakalant is most often used intravenously to stop recent-onset AF. A long-term oral preparation, however, is in development. Several placebocontrolled studies have shown vernakalant to be effective in eliminating AF in about $50 \%$ of patients with limited side effects ${ }^{16}$, 17 . In these studies, vernakalant was most effective for treatment of recent-onset AF, but rarely effective at all for long-standing AF. Common side effects of vernakalant include nausea, sneezing and dysgeusia. The FDA has recommended vernakalant as an intravenous treatment for recent-onset AF.

The 'Pill-in-the-poket' approach may be used in selected, symptomatic patient with infrequent episodes of AF. Oral propafenone $(450-600 \mathrm{mg}$ ) or flecainide (200-300mg) is taken when symptoms of AF occur ${ }^{18}$. 


\subsection{Electrical cardioversion}

Synchronised external direct current cardioversion is a safe procedure with success rates of $70-90 \%{ }^{19}$. It is used acutely in patients who are haemodynamically compromised or electively as an alternative to pharmacological cardioversion. Electrical cardioversion is usually done under conscious sedation. If this is unsuccessful, adjunctive antiarrhythmic treatment with class III agents such as dofetilide, sotalol, and amiodarone can help to restore sinus rhythm.

\subsection{Maintenance of sinus rhythm}

Class III antiarrhythmic agents have an important role as a part of cardioversion strategy and maintaining sinus rhythm. Amiodarone, which is the hallmark drug in this group and most frequently used antiarrhythmic drug for AF treatment, is a relatively safe and effective drug but frequent adverse effects like thyroid dysfunction, pulmonary fibrosis, dermatological changes, and ophthalmic involvement have been reported with its long-term use $^{20}$.

Dronedarone is a benzofuran-derivate of amiodarone with the same electropharmacological profile36 but without side effects on the pulmonary system ${ }^{21}$. It has a shorter half-life than amiodarone ( 1 - 2 days). The recommended oral dose of dronedarone is $400 \mathrm{mg}$ twice a day with meals. The ANDROMEDA study was terminated prematurely because of increased mortality due to the worsening of heart failure in the dronedarone group. Therefore, dronedarone is contraindicated in patients with moderate to severe heart failure ${ }^{26}$. The major adverse cardiac effects of dronedarone are bradycardia and QT prolongation. Torsades de pointes have been reported ${ }^{22}$. Cases of rare but severe hepatic injury associated with use of dronedarone reported. Periodic monitoring of liver-function test should be done especially in the first six months of treatment.

Dronedarone was approved by the American FDA in March, 2009, for sinus-rhythm maintenance in patients with a history of atrial fibrillation/flutter with ejection fraction greater than $35 \%$.

\subsection{Reduction of thromboembolic risk}

Atrial fibrillation can predispose clot formation in the left atrium and consequently ischemic stroke and extra cranial thromboembolism ${ }^{33}$. When stroke occurs in association with atrial fibrillation, patients have a greater mortality and morbidity, longer hospital stays, and greater disability than those without AF. If AF persists for two days, left atrium thrombosis could be seen in $5-14 \%$ of patients ${ }^{34}$. It might, subsequently, become fragmented and embolize to the peripheral atrial system ${ }^{35}$.

Pooled data from trials comparing antithrombotic treatment with placebo have shown that warfarin reduces the risk of stroke by $62 \%$ (95\% confidence interval $48 \%$ to $72 \%$ ) and that aspirin alone reduces the risk by $22 \%$ ( $2 \%$ to $38 \%$ ). Overall, in high risk patients, warfarin was better than aspirin in preventing strokes, with a relative risk reduction of $36 \%(48 \%$ to $72 \%)$. The risk of major haemorrhage with warfarin was twice that with aspirin $^{36}$.

Anticoagulation treatment needs to be tailored individually for patients on the basis of age, comorbidities, and contraindications. In patients with valvular heart disease or high-risk individuals (according to the $\mathrm{CHADS}_{2}$ or $\mathrm{CHA}_{2} \mathrm{DS}_{2} \mathrm{VAS}_{\mathrm{C}}$ scoring), warfarin is the drug of choice. In low-risk conditions, aspirin can be used ${ }^{37}$. 
Oral anticoagulation therapy with warfarin proved superior to clopidogrel plus ASA for prevention of vascular events in AF patients. Treatment with clopidogrel plus ASA was associated with bleeding risk similar to treatment with warfarin ${ }^{38}$. In the ACTIVE-A trial, AF patients for whom oral anticoagulation with warfarin was considered unsuitable, the addition of clopidogrel to ASA reduced the risk of major vascular events, especially stroke, and increased the risk of major hemorrhage ${ }^{39}$.

Dabigatran is a new, potent, direct and competitive inhibitor of thrombin. Its half-life is 12 to 17 hours, and it does not require regular monitoring. AF patients receiving Dabigatran $110 \mathrm{mg}$ twice daily had similar rates of stroke and systemic embolism compared with those using warfarin, but with lower rates of major bleeding. At a dose of $150 \mathrm{mg}$ twice daily, the rate of stroke and systemic embolism is lower but the rate of major bleeding is similar to warfarin ${ }^{40}$.

Apixaban, a novel factor Xa inhibitor, was tested in the AVERROES trial in patients unsuitable for warfarin therapy and at increased risk of stroke. The trial was stopped prematurely because of clear benefit in favor of apixaban, compared to aspirin ${ }^{41}$.

\subsection{Non-pharmacological therapy}

Many non-pharmacological treatments have been developed for the management of AF and some even afford a possible "cure".

\subsection{Radiofrequency catheter ablation}

The past decade has witnessed radiofrequency catheter ablation of AF evolve from an experimental procedure to an important treatment option for many patients with AF. Randomized controlled trials now confirm that left atrial ablation is superior to antiarrhythmic drug therapy in maintaining sinus rhythm over time ${ }^{52-54}$.

Curative catheter ablation techniques initially attempted to mimic the lesions created by the surgical Maze procedure, resulting in limited success with a substantial complication rate. In 1998, Haissaguerre et al. first demonstrated that pulmonary veins (PVs) provided focal firings triggering the occurrence of paroxysmal $\mathrm{AF}^{3}$. They showed that as many as $94 \%$ of such triggers originated from the PVs and that the elimination of these foci by radiofrequency (RF) energy applications in the PVs could cure the paroxysmal form of AF, which became the cornerstone of curative ablation of AF. However, it turned out that high recurrence rates of $\mathrm{AF}$ and late development of PV stenosis were often associated with this procedure ${ }^{43}$. Subsequently, a more advanced technique attempting to isolate the PV muscle sleeves form the left atrium evolved.

Among various procedures to isolate the PV muscle sleeves from the LA initially employed by several investigators, two approaches predominated: namely, segmental ostial ablation at sites where localized conductions between the PV and the LA were electrophysiologically identified ${ }^{44}$, and anatomically guided circumferential PV ablation encircling individual PVs ${ }^{45}$.

Presently, almost all centers empirically isolate all four PVs not at the ostium but outside the tubular portion of the PV to avoid the risk of venous stenosis and improve procedural efficacy. Because the PV is funnel-shaped with a large proximal end (referred to as the antrum), which blends into the posterior wall of the LA, isolation of the PV and the surrounding antral tissue has become the current goal of this procedure.

In order to eliminate the substrate for maintaining $\mathrm{AF}$, the efficiency of two additional adjunctive ablation strategies of PV isolation have been described. The linear lesions are 
made at the roof between the contralateral superior PVs (roof line) and at the isthmus between the mitral valve and the left inferior PV (mitral isthmus line) ${ }^{46,47}$. This concept improved the AF-free ratio from 69 to $87 \%$ in paroxysmal AF cases, although epicardial RF applications were required in $60 \%$ of cases to achieve the mitral isthmus block.

Currently, the most popular method for AF substrate modification in the atrium is to apply RF energy and create lesions targeting the areas with complex fractionated atrial electrograms (CFAEs) ${ }^{48}$. CFAEs are believed to represent slow conduction or pivot points where wavelets turn around at the end of arcs of functional blocks. Although the concept of this method is well accepted, its role in ablation strategies has not yet been fully established. CFAE ablation targets only the substrate to perpetuate AF, and only modest efficacy of this method alone for chronic AF has been reported so far ${ }^{49}$. More recently, CFAE ablation has been achieving a general consensus as one of the combination strategies for modifying AF substrates.

Ablation treatment is successful in approximately $60 \%$ to $70 \%$ of patients that $10 \%$ to $40 \%$ of patients require a second ablation procedure, and that $10 \%$ to $15 \%$ still need antiarrhythmic drugs ${ }^{50}$.

Success rates for catheter-based ablation are lower in patients with persistent atrial fibrillation than in those with paroxysmal AF. In addition, the chances of a successful outcome are lower in those with marked dilation of the left atrium. Oral and colleagues51 reported $75 \%$ recurrence rate in patients with persistent $\mathrm{AF}$, compared with $29 \%$ in patients with paroxysmal AF.

\subsection{Ablation strategy for chronic atrial fibrillation}

Multiple strategies of various procedures, including PV isolation, anatomy- or electrogramguided left-atrial ablation, linear ablation and thoracic vein isolation, have been developed. Each strategy performed alone has been shown to yield similar rates of outcome $(50-70 \%$ success), suggesting the various co-existing targets and factors as the modifiers of the AF substrates. Haïssaguerre et al. developed stepwise multifaceted ablation method for chronic $\mathrm{AF}$, which could integrate different (electrogram- and anatomy based) approaches $55-57$. They combined the approaches of PV isolation, electrogram-based ablation targeting CFAEs, linear ablation at the LAroof and the mitral isthmus and right atrial ablation (in some cases). Up to now, no single strategy is uniformly effective in patients with persistent and longstanding persistent AF.

\subsection{Indication for catheter ablation}

Catheter ablation should generally not be the first-line therapy for atrial fibrillation. The primary indication for it is symptomatic atrial fibrillation that is refractory to at least one class 1 or class 3 antiarrhythmic drug or the inability of a patient to tolerate these drugs. Another indication is in patients in whom rapid atrial fibrillation is determined to be the cause of tachycardia-mediated cardiomyopathy resulting in heart failure, reduced ejection fraction, or both. Studies have been performed in which catheter ablation was used as firstline therapy. The expert consensus committee ${ }^{2}$ recognized this but did not fully support the practice. The decision to proceed with catheter ablation must be individualized on the basis of the risk of complications, the likely benefits, and the likelihood of success.

Recent guidelines have class I recommendation for ablation in selected patients with significantly symptomatic paroxysmal AF and failed treatment with an antiarrhythmic drug 
and have normal or mildly dilated left atria, normal or mildly reduced LV function, and no severe pulmonary disease, when performed in experienced centers.

An absolute contraindication to catheter ablation is left atrial thrombus. Because of the risk of dislodging an existing thrombus during the procedure and causing a stroke, patients with persistent atrial fibrillation who are in atrial fibrillation at the time of the procedure should undergo trans esophageal echocardiography to screen for thrombus.

\subsection{Complications of RFA}

The most common complication associated with catheter ablation of AF is symptomatic or asymptomatic pulmonary vein stenosis (defined as a $>70 \%$ reduction in lumen diameter), with an overall incidence of $1.6 \%$. Somewhat less common are cardiac tamponade $(0.7 \%)$, pericardial effusion $(0.6 \%)$, periprocedural stroke $(0.3 \%)$, and periprocedural transient ischemic attack $(0.2 \%)$. The overall mortality rate is $0.7 \% 58$.

It is clear that catheter ablation is more effective than AAD therapy in treating AF. However because of associated complication catheter ablation of AF should be considered after a patient has failed attempts at treatment with 1 or more AAD.

\subsection{The surgical maze procedure}

Surgeons were the first ones to treat AF effectively and reverse it to sinus rhythm. James Cox described a series of surgical procedures known as Cox-Maze technique. The maze procedure is based on the concept that a critical mass of atrial tissue is needed to allow multiple waves of depolarisation to spread. This surgical approach was directed to divide both right and left atria by a series of cuts and sutures to redirect the electrical impulse to close-end paths. This operation also included the exclusion of both atrial appendages and the isolation of the four pulmonary veins and the posterior wall of the left atrium. Nowadays, cryotherapy, bipolar radiofrequency, and ultrasounds are the most used energy sources.

Although very effective, with over $91 \%$ patients maintaining sinus rhythm at 10 years, few surgical groups performed the Cox-Maze procedure due to the aggressiveness of it, with long suture lines and prolonged myocardial ischemic times 59,60 . Preoperative AF is associated with worse survival rates after valvular or coronary surgery. Furthermore, patients with successful maze procedures have shown better long-term survival rates, higher freedom from stroke, and thromboembolic events, improved ventricular ejection fraction and exercise tolerance. All the above factors have expanded the indications for the surgical treatment of concomitant AF to most patients with coronary or valvular surgery.

In addition, minimally invasive approaches have been described in the last five years with very good results for isolated paroxysmal or persistent AF. Nevertheless, prospective randomized trials are necessary to confirm their long-term results, compared to catheter ablation.

\subsection{Pacing for atrial fibrillation}

Atrial-based pacing, in either single- or dual-chamber mode, reduced the incidence of AF in several prospective multicenter studies $62-67$. More recently, a variety of preventive atrial pacing strategies, including continuous overdrive pacing, pacing in response to atrial premature beats, postmode switch and postexercise pacing therapies, were developed to reduce the burden of AF among patients with known atrial tachyarrhythmias ${ }^{68-73}$.

However, the magnitude of AF prevention due to dedicated preventive pacing algorithms and the identification of responder candidates remains unclear ${ }^{74-76}$. 


\subsection{Atrioventricular node ablation}

Atrioventricular (AV) node ablation provides highly effective control of ventricular rate in patients with AF. Catheter ablation of AV node is a palliative but irreversible procedure and is therefore reasonable in patients in whom pharmacological rate control, or rhythm control with drugs and/or ablation therapy has failed. In such patients, AV node ablation improves quality of life and renders mortality similar to death rates in the general population. It is reasonable to assume that patients with LV systolic dysfunction may require biventricular pacing after $\mathrm{AV}$ node ablation to prevent deterioration of $\mathrm{LV}$ function. In patients without LV dysfunction, it is not established at present whether biventricular pacing is needed: some data suggest that biventricular pacing may be beneficial, 77 while others demonstrate similar benefits with right ventricular pacing.

\subsection{Obliteration of the left atrial appendage}

The left atrial appendage (LAA) is considered the main site of atrial thrombogenesis.Thus, occlusion of the LAA may therefore be an effective way to reduce thromboembolic risk. Surgical closure is recommended only as an adjunctive procedure in patients undergoing mitral valve surgery. However devices have been developed that allows percutaneous LAA closure via the transeptal approach. This may be appropriate for patients who are not suitable for anticoagulation ${ }^{78}$. Further trials are needed to evaluate its long term safety and efficacy.

\subsection{Rheumatic valvular heart disease and atrial fibrillation}

$\mathrm{AF}$ is frequently associated with rheumatic valvular heart disease (RVHD). Valvular heart disease is one of risk factors for development of AF. The frequency of RVHD has decreased in developed but RVHD constitutes a significant burden on healthcare in developing countries.

The risk of thromboembolism in patients with RVHD and AF is high. The stroke risk increases 17-fold if patients have rheumatic heart disease and AF, compared with agematched controls ${ }^{79}$. AF worsens hemodynamics in patients with RVHD as absent atrial kick and irregular ventricular rhythm lead to a fall in cardiac output.

Results of randomized trials evaluating strategies for heart rate control or rhythm control is not necessarily acceptable for patients with RVHD and AF, because the majority of patients in these trials were non-RVHD. In patients with RVHD and AF, the maintenance of sinus rhythm can be expected to improve mortality and QOL. It is suggested that in RVHD and $\mathrm{AF}$ if there is no significant valvular compromise necessitating intervention and if the left atrium size is not more than $6.0 \mathrm{cms}$, rhythm control with amiodarone facilitated by electrical cardioversions should be the strategy ${ }^{82}$. If attempts to maintain SR fail over one year's time, rate control measures should suffice In young patients and those with RVHD but no significant valve compromise, restoring and maintaining SR should be attempted.

Patients receiving mechanical valve replacement need to continue anticoagulant therapy. It is unclear whether or not the maintenance of sinus rhythm influences clinical outcome for thromboembolism in these patients. However, the maintenance of sinus rhythm is important patients receiving tissue valve replacement, or balloon intervention, because they are likely to discontinue anticoagulant therapy.

If AF persists, electrical and pharmacologic cardioversion are effective in restoring sinus rhythm, and the administration of antiarrhythmic drugs may be effective in preventing 
AF80. However, once AF has developed in patients with RVHD, these drugs may not be effective in restoring sinus rhythm because of the pathological changes that develop in the atrium and predispose to AF.

Surgery for AF should be utilized for patients with associated RVHD undergoing valve surgery. The probability of spontaneous conversion to SR after isolated mitral valve surgery is less than $10 \%$. Patients who return to SR after mitral valve replacement or repair demonstrate better survival and freedom from adverse events.

After the success of the Cox maze III procedure in treating AF, several surgeons began to add the maze procedure as an adjunct to mitral valve surgery to treat both problems ${ }^{81}$. Successful restoration of SR has been achieved in $70-96 \%$ of patients.

\section{Conclusion}

Recent developments in pharmacological and non-pharmacological therapy have opened a new horizon in management of AF. Cure of AF has, however become a realistic goal albeit in limited number of patients and will remain a challenge for years to come.

\section{References}

[1] Wyse DG, Waldo AL, DiMarco JP, Domanski MJ, Rosenberg Y, Schron EB, Kellen JC, Greene HL, Mickel MC, Dalquist JE, Corley SD; Atrial fibrillation follow-up investigation of rhythm management (AFFIRM) investigators. A comparison of rate control and rhythm control in patients with atrial fibrillation. N Engl J Med 2002;347:1825-1833.

[2] Calkins H, Brugada J, Packer DL, et al. HRS/EHRA/ECAS expert consensus statement on catheter and surgical ablation of atrial fibrillation: recommendations for personnel, policy, procedures and follow-up. A report of the Heart Rhythm Society (HRS) Task Force on Catheter and Surgical Ablation of Atrial Fibrillation developed in partnership with the European Heart Rhythm Association (EHRA) and the European Cardiac Arrhythmia Society (ECAS); in collaboration with the American College of Cardiology (ACC), American Heart Association (AHA), and the Society of Thoracic Surgeons (STS). Endorsed and approved by the governing bodies of the American College of Cardiology, the American Heart Association, the European Cardiac Arrhythmia Society, the European Heart Rhythm Association, the Society of Thoracic Surgeons, and the Heart Rhythm Society. Europace 2007; 9:335-379.

[3] Haissaguerre M, Jais P, Shah DC, Takahashi A, Hocini M, Quiniou G, et al. Spontaneous initiation of atrial fibrillation by ectopic beats originating in the pulmonary veins. $\mathrm{N}$ Engl J Med 1998;339: 659-66.

[4] Tsai CF, Tai CT, Hsieh MH, Lin WS, Yu WC, Ueng KC, et al. Initiation of atrial fibrillation by ectopic beats originating from the superior vena cava: electrophysiological characteristics and results of radiofrequency ablation. Circulation 2000;102:67-74.

[5] Hwang C, Karagueuzian HS, Chen PS. Idiopathic paroxysmal atrial fibrillation induced by a focal atr discharge mechanism in the left superior pulmonary vein: possible roles of the ligament of Marshall. J Cardiovasc Electrophysiol 1999;10:636-48.

[6] Allessie MA, Konings K, Kirchhof CJ, Wijffels M. Electrophysiologic mechanisms of perpetuation of atrial fibrillation. Am J Cardiol 1996; 77: 10-23A. 
[7] Fareh S, Villemaire C, Nattel S. Importance of refractoriness heterogeneity in the enhanced vulnerability to atrial fibrillation induction caused by tachycardiainduced atrial electrical remodeling. Circulation 1998;98:2202-9.

[8] Singh J, Braich JS. Recent advances in pharmacotherapy of atrial fibrillation. Indian J Pharmacol 2009;41:153-157.

[9] Bajpai A, Savelieva I, Camm AJ. Treatment of atrial fibrillation. Br Med Bull 2008;88:75-94

[10] Van Gelder IC, Crijns HJ, Tieleman RG, Brugemann J, De Kam PJ, Gosselink AT, et al. Chronic atrial fibrillation: success of serial cardioversion therapy and safety of oral anticoagulation. Arch Intern Med 1996; 156: 2585-92

[11] Volgman AS, Soble JS, Neumann A, Mukhtar KN, Iftikhar F, Vallesteros A, et al. Effect of left atrial size on recurrence of atrial fibrillation after electrical cardioversion: atrial dimension versus volume. Am J Card Imaging 1996;10:261-5.

[12] Consensus Conference on Atrial Fibrillation in Hospital and General Practice. Final consensus statement. Proc R Coll Physicians Edinb 1999;suppl 6: 2-3.

[13] Albers GW, Dalen JE, Laupacis A, Manning WJ, Petersen P, Singer DE. Antithrombotic therapy in atrial fibrillation. Stroke 2001; 119: 194-206S.

[14] Wyse DG, Waldo AL, DiMarco JP, Domanski MJ, Rosenberg Y, Schron EB, Kellen JC, Greene HL, Mickel MC, Dalquist JE, Corley SD; Atrial fibrillation follow-up investigation of rhythm management (AFFIRM) investigators. A comparison of rate control and rhythm control in patients with atrial fibrillation. N Engl J Med 2002;347:1825-1833.

[15] Martinez-Marcos FJ, Garcia-Garmendia JL, Ortega-Carpio A, Fernandez-Gomez JM, Santos JM, Camacho C. Comparison of intravenous flecainide, propafenone, and amiodarone for conversion of acute atrial fibrillation to sinus rhythm. Am J Cardiol 2000;86:950-3.

[16] Roy D, Pratt CM, Torp-Pedersen C, Wyse DG, Toft E, Juul-Moller S, et al. Vernakalant hydrochloride for rapid conversion of atrial fibrillation: a phase 3, randomized, placebo-controlled trial. Circulation. 2008 Mar 25;117(12):1518-25.

[17] Kowey PR, Dorian P, Mitchell LB, Pratt CM, Roy D, Schwartz PJ, et al. Vernakalant hydrochloride for the rapid conversion of atrial fibrillation after cardiac surgery: a randomized, double-blind, placebo-controlled trial. Circ Arrhythm Electrophysiol

[18] Alboni P, Botto GL, Baldi N, Luzi M, Russo V, Gianfranchi L, Marchi P,Calzolari M, Solano A, Baroffio R, Gaggioli G. Outpatient treatment of recent-onset atrial fibrillation with the 'pill-in-the-pocket' approach. N Engl J Med 2004;351:2384-2391.

[19] Van Gelder IC, Crijns HJ, Van Gilst WH, Verwer R, Lie KI. Prediction of uneventful cardioversion and maintenance of sinus rhythm from direct-current electrical cardioversion of chronic atrial fibrillation and flutter. Am J Cardiol 1991;68:41-6.

[20] Doyle JF, Ho KM. Benefits and risks of long-term amiodarone therapy for persistent atrial fibrillation: a meta-analysis. Mayo Clin Proc 2009;84:234-342.

[21] Le Heuzey JY, De Ferrari GM, Radzik D, et al. A Short-Term, Randomized,DoubleBlind, Parallel-Group Study to Evaluate the Efficacy and Safety of Dronedarone versus Amiodarone in Patients with Persistent Atrial Fibrillation:The DIONYSOS Study. J Cardiovasc Electrophysiol. 2010;21:597- 605.

[22] Hohnloser SH, Crijns HJ, van Eickels M: for the ATHENA Investigators. Effectof dronedarone on cardiovascular events in atrial fibrillation $\mathrm{N}$ Engl J Med. 2009;360:668-78. 
[23] Bernard EO, Schmid ER, Schmidlin D, Scharf C, Candinas R, Germann R. Ibutilide versus amiodarone in atrial fibrillation: a double-blinded, randomized study. Crit Care Med 2003;31:1031-1034.

[24] Giudici MC, Fischer WJ 3rd, Cervantes DC, Schrumpf PE, Paul DL, Sentman KE, Serra VL, Barold SS. Ibutilide therapy for atrial fibrillation: 5-Year experience in a community hospital. J Cardiovasc Nurs 2008;23:484-488.

[25] Torp-Pedersen C, Moller M, Kober L, Camm AJ. Dofetilide for the treatment of atrial fibrillation in patients with congestive heart failure. Eur Heart J 2000;21:1204-1206.

[26] Køber L, Torp-Pedersen C, McMurray JJ, Gøtzsche O, Lévy S, Crijns H, Amlie J, Carlsen J; Dronedarone study group. Increased mortality after dronedarone therapy for severe heart failure. N Engl J Med 2008;358:2678-2687.

[27] Fuster V, Rydén LE, Cannom DS, Crijns HJ, Curtis AB, Ellenbogen KA, Halperin JL, Heuzey JYL, Kay GN, Lowe JE, Olsson SB, Prystowsky EN, Tamargo JL, Wann S. ACC/AHA/ESC 2006 Guidelines for the Management of Patients with Atrial FibrillationExecutive Summary. JACC 2006;48:854-906.

[28] Segal OR. Rate control for atrial fibrillation: one drug or two? Postgrad 2009;85:281-282.

[29] Van Gelder IC, Groenveld HF, Crijns HJ, et al. Lenient versus strict rate control in patients with atrial fibrillation. N Engl J Med. 2010;362:1363-73.

[30] Freudenberger RS, Wilson AC, Kostis JB; AFFIRM investigators and committees. Comparison of rate versus rhythm control for atrial fibrillation in patients with left ventricular dysfunction (from the AFFIRM study). Am J Cardiol 2007;100:247-252.

[31] Van Gelder IC, Hagens VE, Bosker HA, Kingma JH, Kamp O, Kingma T, Said SA, Darmanata JI, Timmermans AJ, Tijssen JG, Crijns HJ; Rate control versus electrical cardioversion for persistent atrial fibrillation study group. A comparison of rate control and rhythm control in patients with recurrent persistent atrial fibrillation. $\mathrm{N}$ Engl J Med 2002;347:1834-1840.

[32] Hohnloser SH, Kuck KH, Lilienthal J. Rhythm or rate control in atrial fibrillation pharmacological intervention in atrial fibrillation (PIAF): a randomized trial. Lancet 2000;356:1789-1794.2

[33] Nieuwlaat R, Prins MH, Le Heuzey JY, Vardas PE, Aliot E, Santini M, Cobbe SM Widdershoven JW, Baur LH, Levy S, Crijns HJ. Prognosis, disease progression, and treatment of atrial fibrillation patients during 1 year: follow-up of the Euro heart survey on atrial fibrillation. Eur Heart J 2008;29:1181-1189

[34] Thambidorai SK, Murray RD, Parakh K, Shah TK, Black IW, Jasper SE, Li J, AppersonHansen C, Asher CR, Grimm RA, Klein AL; ACUTE investigators. Utility of transesophageal echocardiography in identification of thrombogenic milieu in patients with atrial fibrillation (an ACUTE ancillary study). Am J Cardiol 2005;96:935-941.

[35] Kavlak ES, Kucukoglu H, Yigit Z, Okcun B, Baran T, Ozkan AA, Kucukoglu S. Clinical and echocardiographic risk factors for embolization in the presence of left atrial thrombus. Echocardiography 2007;24:515-521.

[36] Fuster V, Ryden LE, Asinger RW, Cannom DS, Crijns HJ, Frye RL, et al. ACC/AHA/ESC guidelines for the management of patients with atrial fibrillation: a report of the American College of Cardiology/American Heart Association Task Force on Practice Guidelines and the European Society of Cardiology Committee for Practice Guidelines and Policy Conferences (committee to develop guidelines for the management of patients with atrial fibrillation) developed in collaboration 
with the North American Society of Pacing and Electrophysiology. Eur Heart J 2001; 22: 1852-923

[37] Menke J, Lüthje L, Kastrup A, Larsen J. Thromboembolism in atrial fibrillation. Am J Cardiol 2010;105:502-510.

[38] Connolly S, Pogue J, Hart R, et al. Clopidogrel plus aspirin versus oral anticoagulation for atrial fibrillation in the Atrial fibrillation Clopidogrel Trial with Irbesartan for prevention of Vascular Events (ACTIVE W): a randomized controlled trial. Lancet. 2006;367:1903-12.

[39] Connolly SJ, Pogue J, Hart RG, et al. Effect of clopidogrel added to aspirin in patients with atrial fibrillation. N Engl J Med. 2009;360:2066 -78.

[40] Connolly SJ, Ezekowitz MD, Yusuf S, Eikelboom J, Oldgren J, Parekh A, Pogue J, Reilly PA, Themeles E, Varrone J, Wang S, Alings M, Xavier D, Zhu J, Diaz R, Lewis BS, Darius H, Diener HC, Joyner CD, Wallentin L; RE-LY steering committee and investigators. Dabigatran versus warfarin in patients with atrial fibrillation. N Engl J Med 2009;361:1139-1151.

[41] Connolly S J, Eikelboom J, Joyner C, Franzosi M G, et al, AVERROES Steering Committee and Investigators. N Engl J Med $2011 ; 364: 806-817$.

[42] Corley SD, Epstein AE, DiMarco JP, Domanski MJ, Geller N, Greene HL, Josephson RA, Kellen JC, Klein RC, Krahn AD, Mickel M, Mitchell LB, Nelson JD, Rosenberg Y, Schron E, Shemanski L, Waldo AL, Wyse DG: Relationships between sinus rhythm, treatment, and survival in the Atrial Fibrillation Follow-up Investigation of Rhythm Management (AFFIRM) study. Circulation 2004;109:1509-1513.

[43] Robbins IM, Colvin EV, Doyle TP, Kemp WE, Loyd JE, McMahon WS, Kay GN. Pulmonary vein stenosis after catheter ablation of atrial fibrillation. Circulation. 1998;98:1769-75.

[44] HaïssaguerreM, Shah DC, Jaïs P, et al. Electrophysiological breakthroughs from the left atrium to the pulmonary veins. Circulation. 2000;102:2463-2465

[45] Pappone C, Rosanio S, Oreto G, Tocchi M, Gugliotta F, Vicedomini G, Salvati A, et al. Circumferential radiofrequency ablation of pulmonary vein ostia: A new anatomic approach for curing atrial fibrillation. Circulation 2000;102:2619-2628.

[46] Hocini M, Jaïs P, Sanders P, Takahashi Y, Rotter M, Rostock T, et al. Techniques, evaluation, and consequences of linear block at the left atrial roof in paroxysmal atrial fibrillation: a prospective randomized study. Circulation. 2005;112:3688-96.

[47] Jais P, Hocini M, Hsu LF, et al. Technique and results of linear ablation at the mitral isthmus Circulation 2004;110:2996-3002.

[48] Nademanee K, McKenzie J, Kosar E, et al. A new approach for catheter ablation of atrial fibrillation: mapping of the electrophysiologic substrate. J Am Coll Cardiol 2004;43:2044-53

[49] Oral H, Chugh A, Good E, Wimmer A, Dey S, Gadeela N, et al. Radiofrequency catheter ablation of chronic atrial fibrillation guided by complex electrograms. Circulation (2007) 115:2606-12.

[50] Crandall MA, Bradley DJ, Packer DL, Asirvatham SJ. Contemporary management of atrial fibrillation: update on anticoagulation and invasive management strategies. Mayo Clin Proc 2009; 84:643-662.

[51] Oral H, Knight BP, Tada $\mathrm{H}$, et al. Pulmonary vein isolation for paroxysmal and persistent atrial fibrillation. Circulation 2002; 105:1077-1081. 
[52] Wazni OM, Marrouche NF, Martin DO, et al. Radiofrequency ablation vs antiarrhythmic drugs as first-line treatment of symptomatic atrial fibrillation: a randomized trial. JAMA 2005; 293:2634-2640.

[53] Jaïs P, Cauchemez B, Macle L, et al. Catheter ablation versus antiarrhythmic drugs for atrial fibrillation: the A4 study. Circulation 2008; 118:2498-2505.

[54] Pappone C, Augello G, Sala S, et al. A randomized trial of circumferential pulmonary vein ablation versus antiarrhythmic drug therapy in paroxysmal atrial fibrillation: the APAF Study. J Am Coll Cardiol 2006; 48:2340-2347.

[55] Haïssaguerre M, Sanders P, Hocini M, et al., J Cardiovasc Electrophysiol, 2005;16:1125-37.

[56] Jaïs P, O’Neill MD, Takahashi Y, et al., J Cardiovasc Electrophysiol, 2006;17(Suppl. 3):S28-36.

[57] Matsuo S, Lim KT, Haïssaguerre M, Heart Rhythm,2007;4:1461-3.

[58] Calkins H, Reynolds MR, Spector P, et al. Treatment of atrial fibrillation with antiarrhythmic drugs or radiofrequency ablation: two systematic literature reviews and meta-analyses. Circ Arrhythm Electrophysiol. 2009;2:349-61

[59] J. L. Cox, "The surgical treatment of atrial fibrillation: IV.Surgical technique," Journal of Thoracic and Cardiovascular Surgery, vol. 101, no. 4, pp. 584-592, 1991.

[60] J. L. Cox, J. P. Boineau, R. B. Schuessler, R. D. Jaquiss, and D. G. Lappas, "Modification of the maze procedure for atrial flutter and atrial fibrillation. I. Rationale and surgical results,Journal of Thoracic and Cardiovascular Surgery, vol. 110, no. 2,pp. 473-484, 1995.

[61] E. Lim, C. W. Barlow, A. R. Hosseinpour et al., "Influence of atrial fibrillation on outcome following mitral valve repair,"

[62] Lamas GA, Lee KL, Sweeney MO, et al, for the Mode Selection Trial in Sinus Node Dysfunction Investigators. Ventricular pacing or dual-chamber pacing for sinusnode dysfunction. N Engl J Med 2002;346:1854 -1862.

[63] Kerr CR, Connolly SJ, Abdollah H, et al, for the Canadian Trial of Physiological Pacing (CTOPP) Investigators. Canadian Trial of Physiologic Pacing: effects of physiologic pacing during long-term follow-up. Circulation 2004;109:357-362.

[64] Connolly SJ, Kerr CR, Gent M, et al. Effects of physiologic pacing versus ventricular pacing on the risk of stroke and death due to cardiovascular causes. Canadian Trial of Physiologic Pacing Investigators. N Engl J Med 2000;342:1385-1391.

[65] Andersen HR, Nielsen JC, Thomsen PE, et al. Long-term follow-up of patients from a randomized trial of atrial versus ventricular pacing for sick sinus syndrome. Lancet 1997;350:1210 -1216.

[66] Delfaut P, Saksena S, Prakash A, et al. Long-term outcome of patients with drugrefractory atrial flutter and fibrillation after single-and dual-site right atrial pacing for arrhythmia prevention. J Am Coll Cardiol 1998;32:1900 -1908.

[67] Lamas GA, Orav EJ, Stambler BS, et al. Quality of life and clinical outcomes in elderly patients treated with ventricular pacing as compared with dual-chamber pacing. Pacemaker Selection in the Elderly Investigators. N Engl J Med 1998;338:1097-104.

[68] Blanc JJ, De Roy L, Mansourati J, et al, for the PIPAF Investigators. Atrial pacing for prevention of atrial fibrillation: assessment of simultaneously implemented algorithms. Europace 2004;6:371-379.

[69] Lee MA, Weachter R, Pollak S, et al. The effect of atrial pacing therapies on atrial tachyarrhythmia burden and frequency: results of a randomized trial in patients with bradycardia and atrial tachyarrhythmias. J Am Coll Cardiol 2003;41:1926 -1932. 
[70] Padeletti L, Purerfellner H, Adler SW, et al, for the Worldwide ASPECT Investigators. Combined efficacy of atrial septal lead placement and atrial pacing algorithms for prevention of paroxysmal atrial tachyarrhythmia. J Cardiovasc Electrophysiol 2003;14:1189-1195.

[71] Levy T, Walker S, Rex S, et al. Does atrial overdrive pacing prevent paroxysmal atrial fibrillation in paced patients? Int J Cardiol 2000;75:91-97.

[72] Lozano IF, Vincent A, Roda J, et al. Paroxysmal atrial fibrillation prevention by pacing in patients with pacemaker indication. Europace 2003;5:267-273.

[73] Israel CW, Hohnloser SH. Pacing to prevent atrial fibrillation. J Cardiovasc Electrophysiol 2003;14(9 Suppl):S20 -S26.

[74] Carlson MD, Ip J, Messenger J, et al. A new pacemaker algorithm for the treatment of atrial fibrillation: results of the Atrial Dynamic Overdrive Pacing Trial (ADOPT). J Am Coll Cardiol 2003;42:627- 633.

[75] Knight BP, Gersh BJ, Carlson MD, et al, for the AHA Writing Group. Role of permanent pacing to prevent atrial fibrillation: science advisory from the AHA Council on Clinical Cardiology and the Quality of Care and Outcomes Research Interdisciplinary Working Group, in collaboration with the Heart Rhythm Society. Circulation 2005;111:240 -243.

[76] Savelieva I, Camm AJ. The results of pacing trials for the prevention and termination of atrial tachyarrhythmias: is there any evidence of therapeutic breakthrough? J Interv Card Electrophysiol 2003;8:103-115.

[77] Gasparini M, Auricchio A, Metra M, Regoli F, Fantoni C, Lamp B, Curnis A,Vogt J, Klersy C. Long-term survival in patients undergoing cardiac resynchronization therapy: the importance of performing atrio-ventricular junction ablation in patients with permanent atrial fibrillation. Eur Heart J 2008;29:1644-1652.

[78] Holmes DR, Reddy VY, Turi ZG, Doshi SK, Sievert H, Buchbinder M, Mullin CM,Sick P. Percutaneous closure of the left atrial appendage versus warfarin therapy for prevention of stroke in patients with atrial fibrillation: a randomised noninferiority trial. Lancet 2009;374:534-542.

[79] Wolf P, Dawber T, Thomas HJ, et al. Epidemiologic assessment of chronic atrial fibrillation and risk of stroke: the Framingham study. Neurology. 1978;28(10):973-977.

[80] Vora A, Karnad D, Goyal V, Naik A, Gupta A, Lokhandwala Y, et al. Control of rate versus rhythm in rheumatic atrial fibrillation: a randomized study. Indian Heart J 2004; 56: 110-116.

[81] Khargi K, Hutten BA, Lemke B, Deneke T. Surgical treatment of atrial fibrillation: a systemic review. Eur J Cardiothorac Surg 2005; 27: 258-265.

[82] Vora A. Management of atrial fibrillation in rheumatic valvular heart disease. Curr Opin Cardiol 2006; 21: 47-50. 


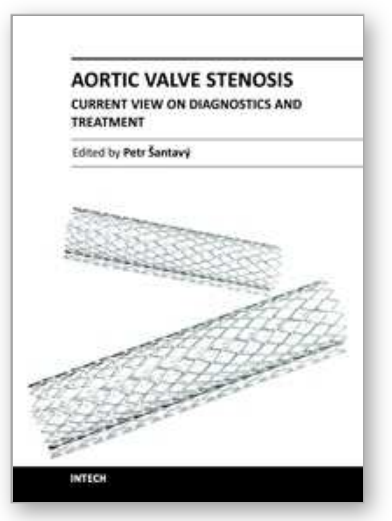

\author{
Aortic Valve Stenosis - Current View on Diagnostics and Treatment \\ Edited by Dr. Petr Santavy
}

ISBN 978-953-307-628-7

Hard cover, 146 pages

Publisher InTech

Published online 22, September, 2011

Published in print edition September, 2011

Currently, aortic stenosis is the most frequent heart valve disease in developed countries and its prevalence increases with the aging of the population. Affecting 3-5 percent of persons older than 65 years of age, it makes a large personal and economical impact. The increasing number of elderly patients with aortic stenosis brings advances in all medical specialties dealing with this clinical entity. Patients previously considered too old or ill are now indicated for aortic valve replacement procedures. This book tries to cover current issues of aortic valve stenosis management with stress on new trends in diagnostics and treatment.

\title{
How to reference
}

In order to correctly reference this scholarly work, feel free to copy and paste the following:

Mohan Nair, Sanjeeb Patra and Vanita Arora (2011). Pharmacologic and Non-Pharmacologic Treatment of Chronic Atrial Fibrillation - With Special Reference to Valvular Atrial Fibrillation in Rheumatic Heart Disease, Aortic Valve Stenosis - Current View on Diagnostics and Treatment, Dr. Petr Santavy (Ed.), ISBN: 978-953307-628-7, InTech, Available from: http://www.intechopen.com/books/aortic-valve-stenosis-current-view-ondiagnostics-and-treatment/pharmacologic-and-non-pharmacologic-treatment-of-chronic-atrial-fibrillation-withspecial-reference-

\section{INTECH}

open science | open minds

\section{InTech Europe}

University Campus STeP Ri

Slavka Krautzeka 83/A

51000 Rijeka, Croatia

Phone: +385 (51) 770447

Fax: +385 (51) 686166

www.intechopen.com

\section{InTech China}

Unit 405, Office Block, Hotel Equatorial Shanghai

No.65, Yan An Road (West), Shanghai, 200040, China

中国上海市延安西路65号上海国际贵都大饭店办公楼 405 单元

Phone: +86-21-62489820

Fax: +86-21-62489821 
(C) 2011 The Author(s). Licensee IntechOpen. This chapter is distributed under the terms of the Creative Commons Attribution-NonCommercialShareAlike-3.0 License, which permits use, distribution and reproduction for non-commercial purposes, provided the original is properly cited and derivative works building on this content are distributed under the same license. 